\title{
SELECTIVE PARAMETRIC SPECIFICITY OF CLUJ-NAPOCA METEOROLOGICAL STATION ACCORDING TO ANNEX 1B OF WMO NO. 8 GUIDE
}

\author{
G.-S. TUDORACHE ${ }^{1,2}$
}

\begin{abstract}
Selective parametric specificity of Cluj-Napoca meteorological station according to Annex 1B of WMO No. 8 Guide. Meteorological metadata are required to be used for all types of measurements. Metadata is information about when, where, how and by whom the meteorological data was measured. Detailed metadata are important to understand the characteristics and limits of measurements, especially for climatology. But detailed metadata, due to their complexity, can greatly reduce their operational use. In the usual practice, the measurement characteristics and limits of a sensor are taken into account at the expense of the environmental conditions in which the measurement of a meteorological parameter takes place. W.M.O., based on the Meteo-France's proposals (M. Leroy, 1998), has defined a classification for some base surface variables to document the environment near a site. Site classification requires assigning a class number for each measured parameter, which varies from 1 to 5 . By convention, a class 1 location complies with WMO regulations. In this paper, the classification criteria set out in Annex 1B of wmo Guide No. 8, are adapted and applied for Cluj-Napoca meteorological station. As a result of applying the classification for Cluj-Napoca Automatic Weather Station, a class number is assigned for the air temperature-humidity, precipitation and wind sensor. The application proposals for the site classification based on results can then be applied to the rest of the meteorological network taking into account the characteristics of the location of a meteorological platform.
\end{abstract}

Keywords: site classification, metadata, meteorological measurement, sensors

\section{INTRODUCTION}

When installing a meteorological station, site selection is a very important task, largely reflected in the quality of the data obtained and implicitly of the climate assessments carried out in the research activity. Internationally, the issue of the respresentativeness and quality of meteorological data is treated with maximum interest, trough the World Meteorological Organisation`s (W.M.O.) specialized committees. The main negative aspects are related to the appearance of high-rise buildings near the meteorological station, the sensor's specifications and the experience of the personnel.

\footnotetext{
${ }^{1}$ Faculty of Geography, University of Bucharest, 1 Nicolae Bălcescu Blvd., Sector 1, 010041, Bucharest, Romania, e-mail: tudorache.george86@yahoo.com

${ }^{2}$ Romanian National Meteorological Administration, 97 Bucuresti-Ploiești St., Sector 1, 013686, Bucharest, Romania, e-mail: george.tudorache@meteoromania.ro
} 
Since it is impossible to maintain a very dense meteorological network, knowing that the measurements are thus punctual, the quality of the data and their ability to express extensible values on large areas of territory is the essence and condition for the quality of studies and climatological research.

Understanting the mechanisms generating certain types of weather, the occurence and evolution of meteorological phenomenas, some of them with a high risk character, variation of the climate, climate change, can only be achieved by processing an important volume of quality data, ensures the elimination of any suspicions.

Theoretically these issues are regulated by W.M.O. - Guide to Meteorological Instruments and Methods of Observation - Sixth edition - WMONo. $8-1996$ (WMO, 2008), which sets out the general conditions necessary for the normal operation of a meteorological station. It also regulates the way the instruments are exposed, this being a determining factor in the measurement of some meteorological elements. In order to maintain the representativeness and, implicitly, the quality of the meteorological data, the Commision for Observing Intruments and Methods recommends that periodic inspections of the meteorological stations are carried out regularly. Internationally, it is noted that both methodological norms and equipment vary from one country to another. Thus, meteorological data must be thoroughly analysed when comparing them. For short periods of 20 years, for example, an increase in the average air temperature may be due to replacement of the sensor, from a higher precision class, sensor errors, observer change, the evelation of some constructions near the meteorological station, but also a realt heating or trends. An increase in the average air temperature of $0.3-0.6{ }^{\circ} \mathrm{C}$ over the past 100 years can not be supported by climatologists unless the data used are rigorously accurate without any of the above mentioned errors.

Traditionally, instruments characteristics are taken into account more than the environment around the platform. Meteo-France proposes a classification of the obstacles in a $100 \mathrm{~m}$ area around the measuring point (M. Leroy, 1998). Based on this proposal W.M.O. establishes the criteria for the meteorological site classification. The site classification implies assignment of a class number between 1 and 5 (where 1 is the most appropriate) for each sensor. A class 5 site where nearby obstacles create an inadequate measurement environment meteorological and which is intended to be representative of a wide area (at least tens of $\mathrm{km}^{2}$ ), is a location where measurements should be avoided.

For some classes, an estimate of possible associated errors or disturbances was indicated. This estimate results from bibliographic studies and/or from comparative tests. In this paper the classification criteria according to Annex 1B are adapted and applied in order to establish a class number according to the environment in which Cluj-Napoca meteorological station is installed. To apply the classification, simple but effective methods are developed based on W.M.O. criteria to avoid high costs and to shorten the execution time. 


\section{DATA AND METHODS}

In order to obtain the classification of the Cluj-Napoca meteorological platform in accordance with W.M.O. Annex 1B regulations, it is necessary to identify the existing obstacles in the $100 \mathrm{~m}$ area around the Automatic Weather Station pole.

Thus, using Google satellite imagery, all obstacles have been mapped into the following main categories: buildings, high vegetation, small vegetation and asphalt/concrete surfaces (but in the case of Cluj-Napoca no significant asphalt/concrete surfaces were identified). As a suggestion, if there is a poor image clarity of Google images, orthofotoplan images can also be used (this is not the case here). Following the vectorising in a GIS software, a map results (Fig. 1) which will be the basis in obtaining the necessary information for the classification. As can be observed in Fig. 1 distances from the center of the meteorological platform to the existing obstacle are important and have been measured and noted, they will be part of the analysis criteria for certain meteorological parameters included in the classification.

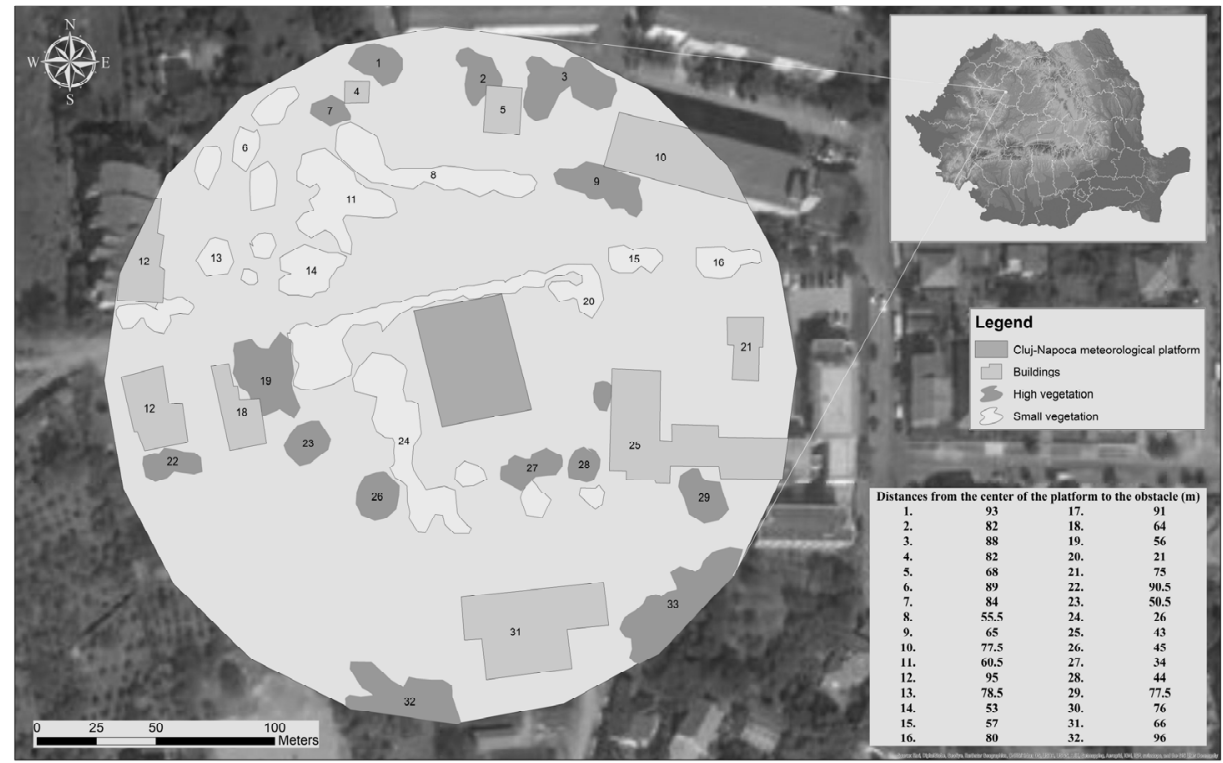

Fig. 1. The obtained image with the vectorized obstacles for Cluj-Napoca meteorological station using GIS software

In Fig. 2 on-site images are presented with the sides of the Cluj-Napoca meteorological platform for exemplifying the horizontal visibility from the center of the platform. These images are documented and stored together with the classification charts done in accordance with the Annex 1B regulations. 
Obstacle identification is necessary but not sufficient to analyze the classification of a meteorological parameter, additional information is essential to determine whether the obstacle infuses the measurements or can be ignored.

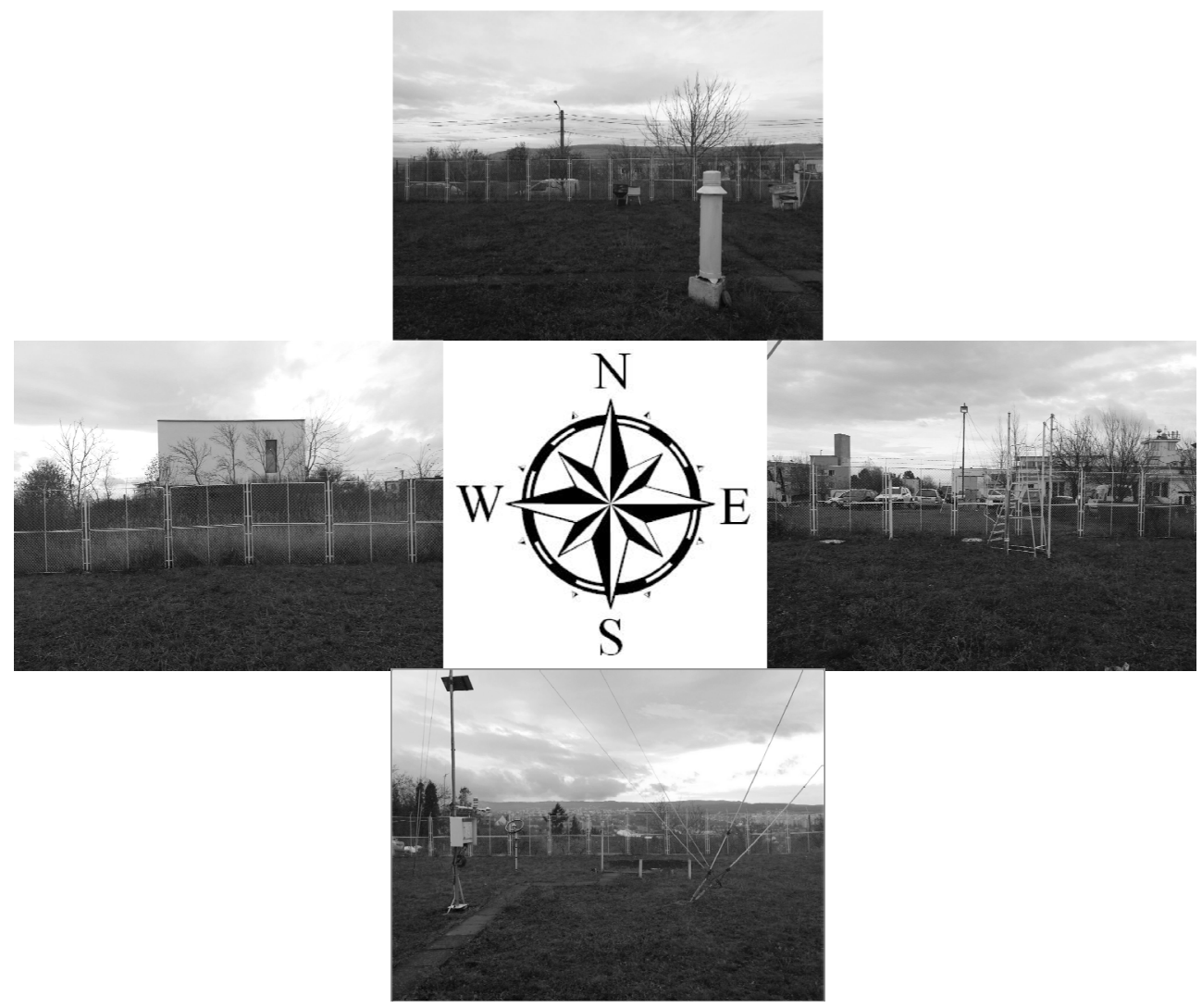

Fig. 2. On-site images of Cluj-Napoca meteorological platform sides (2017)

In the second phase of the classification, after identifying the visible obstacles using satellite imagery, a table was compiled and filled on site with measured information about the nearby obstacles. The table contains columns regarding the obstacle height, length and width, the material from which the it is built/the type of the vegetation and other observation regarding the slope of the land, soil type, heat sources and asphalt or concrete surfaces (Tab. 1). Filling the table with the above mentioned information was done on site by measuring, assessing and documenting the materials from which the nearby obstacles are built of. 
Table 1. Cluj-Napoca meteorological station - required information table resulted from obstacle vectorization and filled with the neccesary details

\begin{tabular}{|c|c|c|c|c|c|}
\hline Obstacole & $\begin{array}{c}\text { Obstacle } \\
\text { height }(\mathrm{m})\end{array}$ & $\begin{array}{l}\text { Obstacle } \\
\text { leght }(\mathrm{m})\end{array}$ & $\begin{array}{l}\text { Obstacle } \\
\text { width }\end{array}$ & $\begin{array}{c}\text { Material } \\
\text { type }\end{array}$ & Observations \\
\hline 4. & $6 / 0$ & 6.5 & 5.7 & Brick & Beneath the platform \\
\hline 5. & $7 / 1$ & 12.7 & 9.6 & $\mathrm{AAC}$ & Partial beneath the platform \\
\hline 10. & $12 / 4$ & 55 & 18 & $\mathrm{AAC}$ & Partial beneath the platform \\
\hline 12. & $6 / 6$ & 13.5 & 11.5 & Brick & Partial beneath the platform \\
\hline 18. & $7 / 6$ & 24 & 11 & AAC & Partial beneath the platform \\
\hline 21. & $6 / 5$ & 18 & 9 & $\mathrm{AAC}$ & Partial beneath the platform \\
\hline 25. & $5 / 5$ & 29 & 13 & $\mathrm{AAC}$ & Partial beneath the platform \\
\hline 30. & $3 / 3$ & 6.5 & 3 & $\mathrm{AAC}$ & Partial beneath the platform \\
\hline 31. & $6 / 0$ & 40 & 23 & $\mathrm{AAC}$ & Beneath the platform \\
\hline Vegetation & $\begin{array}{l}\text { Vegetation } \\
\text { height (m) }\end{array}$ & $\begin{array}{l}\text { Vegetation } \\
\text { lenght (m) }\end{array}$ & $\begin{array}{l}\text { Vegetation } \\
\text { width (m) }\end{array}$ & $\begin{array}{l}\text { Vegetati } \\
\text { on type }\end{array}$ & Observations \\
\hline 1. & $5 / 0$ & 10 & 6.5 & Tree & Beneath the platform \\
\hline 2. & $5 / 0$ & 8.1 & 5.6 & Tree & Beneath the platform \\
\hline 3. & $6 / 0$ & 6.5 & 5 & Tree & Beneath the platform \\
\hline 6. & $1 / 1$ & 6 & 4 & Bush & Beneath the platform \\
\hline 7. & $5 / 4$ & 5.8 & 5 & Tree & Partial beneath the platform \\
\hline 8. & $1 / 1$ & 43 & 3 & Tree & Partial beneath the platform \\
\hline 9. & $5 / 5$ & 7 & 4 & Tree & Partial beneath the platform \\
\hline 11. & $1 / 1$ & 8 & 8 & Tree & Partial beneath the platform \\
\hline 13. & $1 / 1$ & 3 & 3 & Tree & Partial beneath the platform \\
\hline 14. & $1 / 1$ & 2 & 2 & Tree & Partial beneath the platform \\
\hline 15. & $1 / 1$ & 3 & 3 & Tree & Partial beneath the platform \\
\hline 16. & $1 / 1$ & 8 & 8 & Tree & Partial beneath the platform \\
\hline 19. & $5 / 5$ & 8 & 8 & Fir & \\
\hline 20. & $1 / 1$ & 37 & 2 & Tree & \\
\hline 22. & $4 / 3$ & 4 & 4 & Tree & Not seen from the platform \\
\hline 23. & $5 / 4$ & 9 & 9 & Tree & \\
\hline 24. & $1 / 1$ & 40 & 4 & Bush & $\begin{array}{l}\text { They were partially cut (about } \\
60 \% \text { ) }\end{array}$ \\
\hline 26. & $3 / 3$ & 8 & 8 & Tree & \\
\hline 27. & $5 / 4$ & 6 & 3 & Tree & \\
\hline 28. & $5 / 4$ & 6 & 6 & Tree & The peaks are visible \\
\hline 29. & $5 / 5$ & 9 & 9 & Tree & The peaks are visible \\
\hline 32. & $4 / 0$ & 10 & 10 & Tree & Beneath the platform \\
\hline 33. & $4 / 4$ & 10 & 10 & & Beneath the platform \\
\hline \multicolumn{3}{|c|}{ The angle (inclination) of the platform field } & \multicolumn{2}{|l|}{$0^{\circ}$} & ----- \\
\hline \multicolumn{3}{|c|}{ Soil type meteorological platform } & \multicolumn{2}{|c|}{ Brown forest } & \\
\hline \multicolumn{3}{|c|}{ Surse de căldură } & \multicolumn{2}{|c|}{$\begin{array}{c}\text { Distance to the } \\
\text { meteorological platform }\end{array}$} & Type of heat source \\
\hline \multicolumn{3}{|l|}{ Parcare } & \multicolumn{2}{|c|}{$40 \mathrm{~m}$} & $\begin{array}{l}\text { Concrete over which asphalt was } \\
\text { poured }\end{array}$ \\
\hline
\end{tabular}

After completing the table with the identified obstacles in the first stage, knowing height, obstacle length and width, in order to have a better virtual view of the platform and obstacles, shapefiles are loaded into Google Earth and 3D images are generated (Fig. 3). 
Images that can also be stored alongside other files and images that complement the classification of the meterological platform location.

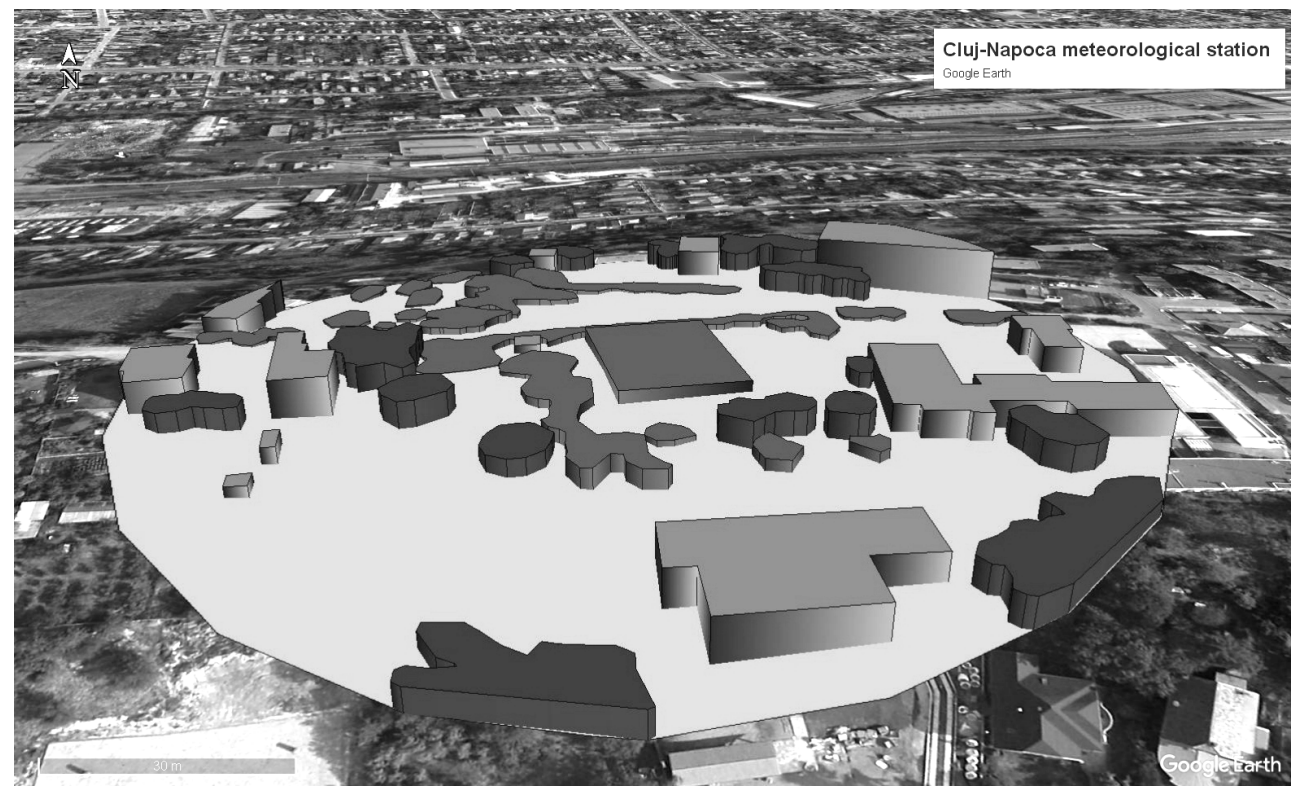

Fig. 3. The obstacle image with the vectorized obstacles for Cluj-Napoca meteorological station transposed in $3 D$ using Google Earth

The last step of the siting classification after obtaining all the information on the obstacles is to compile classification sheet for the station where class numbers are assigned for each meteorological parameter classified using Annex 1B regulations. These classification sheet represent a summary of the classes attributed to the meteorological parameters measured at the station, supported by the image with the vectorized obstacles and other special observations. The classification sheet can be stored in the metadata database and provide a quality flag for the meteorological data requested by the user.

\section{OBJECTIVES AND RESULTS}

The main objective of the classification is to inform the data user/beneficiary about the quality of the data by providing the necessary information about the measurement methods and conditions.

The metadata reconstruction process is important for ensuring the quality of the data string. Restoring the metadata is necessary and useful to meet the requirements of the INSPIRE Directive of the European Union (since May 2007), which includes the INSPIRE Metadata Regulation document. Siting classification is useful to document and analyze the impact of urban development on A.W.S. 
locations. Within a national meteorological network, for all meteorological station will be compiled a classification sheet (Fig. 5).

To help the technician determine the classification of the meteorological parameters included in the site classification, synthesis files have been prepared that use in the background the calculation formulas and the criteria contained in Annex 1B (Fig. 4).

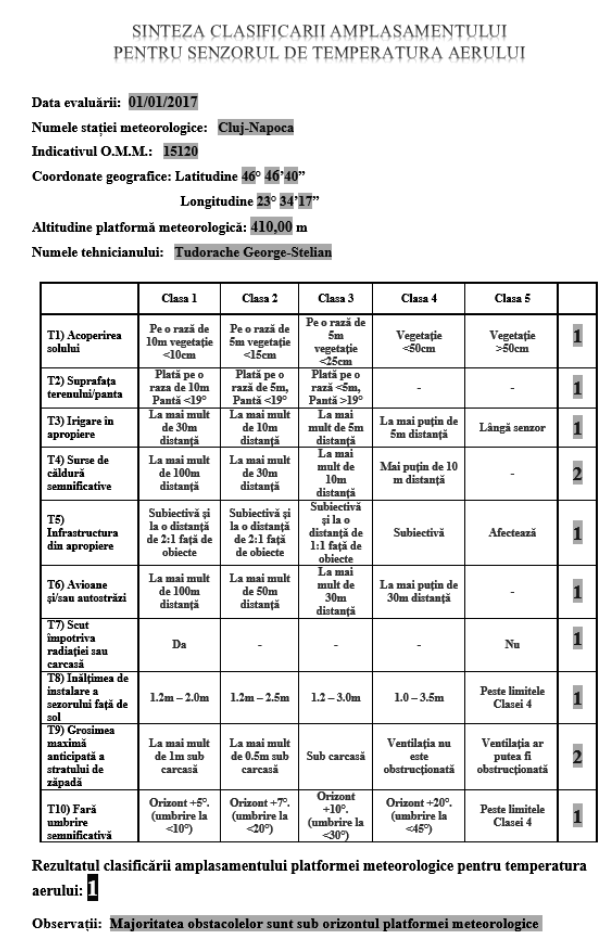

Fig. 4. Printscreen of site classification synthesis file (in Romanian) for air temperature parameter for Cluj-Napoca meteorological station

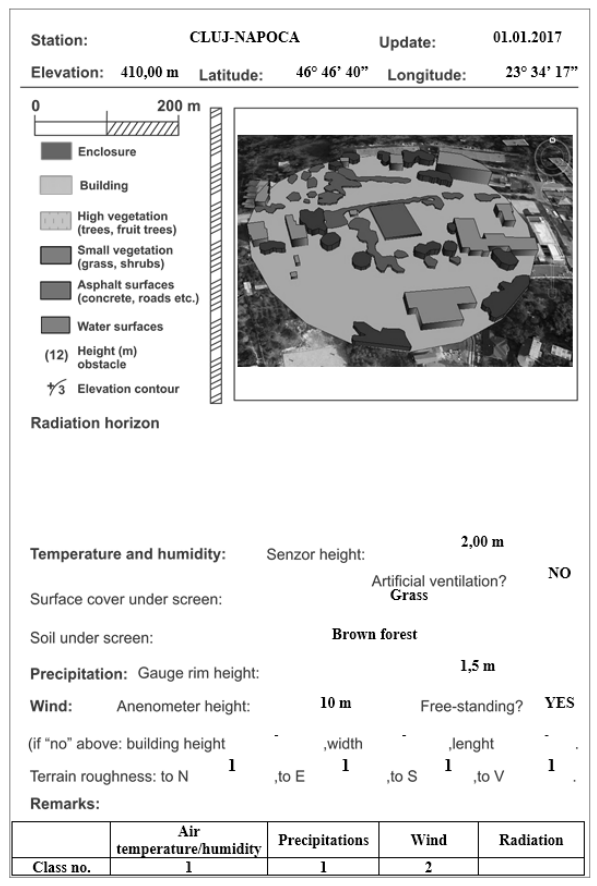

Fig. 5. Printscreen of site classification chart (in English) for Cluj-Napoca meteorological station according to Annex $1 B-W M O N o .8$

The classification sheet needs to be revised periodically at least 5 years, according to W.M.O. regulations. Due to the technological progress in building construction, the emergence of new big obstacles may occur within 1 year, so it is recommended that the changes in the surrounding environment of the platform to be analyzed annually at least visually.

In the case of Cluj-Napoca meteorological station following the application of the siting classification the temperature/humidity parameter received a class 1, the precipitation parameter received a class 2 and wind measurements received a class 2.

Classification methodology is in early stages trying to implement methods that are fast and efficient but not costly in order to compile the classification, this is 
the reason why for the radiation meteorological parameter, a class number could not be determined mainly due to the lack of a clear procedure.

\section{CONCLUSIONS}

The primary objective of the classification is to document the presence of the obstacles near the measuring site. By linking the measurements to their associated uncertaintly level, this classification can be used to define the maximum class assigned to a meteorological station so that it can be included in a particular network or used in a particular application.

The classifications main advantage is being simple and therefore easy to use. Unfortunately, siting classification as defined does not allow the measurements to be corrected. Correction methods remain possible but independent of the meteorological platform classification. There is a clear limitation, but this classification allows easy documentation of the "quality" of the meteorological network. The results of the classification are important and so are the methodology that resulted by applying different methods and intruments (software packages). In the end, the siting classification represents a "win-win" situation both for the meteorological network owner and for the data user.

In the case of the Cluj-Napoca meteorological platform, the parametric classification assigns a general class number of 1 (Fig. 4), meaning that the data measured at this location is in accordance with the W.M.O. regulations and the data user can apply the dataset in most of its studies or applications.

\section{REFERENCES}

1. Leroy, M., in WMO (1998), Meteorological measurement representativity, nearby obstacles influence, Papers Presented at the WMO Technical Conference on Meteorological and Environmental Instruments and Methods of Observation (TECO-1998), Instruments and Observing Methods Report No. 70, p. 51

2. Leroy, M., in: WMO (2010), Sites Classification, Papers Presented at the WMO Technical Conference on Meteorological and Environmental Instruments and Methods of Observation (TECO-2010), Instruments and Observing Methods Report No. 104

3. Raliță, I. (2005), Criterii de reprezentativitate a platformelor stațiilor meteorologice, ISBN-10 973-0-04655-7, ISBN-13 978-973-0-04655-7. București

4. Zahumensky, I., (2015), Maintenance of Accurate Metadata for all Automatic Weather Station Installations, CBS/OPAG-IGOS/ET AWS-3.

5. *** WMO (2008), Guide to Meteorological Instruments and Methods of Observation, WMO-No.8

6. *** WMO (2008), Annex 1.B - Siting classifications for surface observing stations on land, WMO-No.8, I.1-19

7. *** WMO (2001), Automatic Weather Station MAWS 301, User's Guide M10077en-A. Vaisala 